Check for updates

Cite this: RSC Adv., 2018, 8, 20686

\title{
Introducing carbon dots to moderate the blue emission from zinc vanadium oxide hydroxide hydrate nanoplates
}

\author{
Peng Huang, (D) a Guodong Yuan, ${ }^{a}$ Tongbo Wei, ${ }^{a}$ Jinmin $\mathrm{Li}^{\star a}$ \\ and Michael N. R. Ashfold (iD *b
}

\begin{abstract}
The relative intensity of the blue component of the total emission from light-emitting diodes (LEDs) can be an important factor when assessing their biological safety. Carbon quantum dots (CQDs) are compatible with many materials and present a high density of multiple surface states; the incorporation of such CQDs thus offers a route to modifying the emission from a given LED matrix. Here we report the fabrication of stable CQD/zinc pyrovanadate $\left(\mathrm{Zn}_{3}(\mathrm{OH})_{2} \mathrm{~V}_{2} \mathrm{O}_{7} \cdot 2 \mathrm{H}_{2} \mathrm{O}\right)$ nanoplate composites via a facile hydrothermal route. Structural and morphological analyses confirm that the nanoplates are hexagonal phase and grew normal to the [0001] direction. X-ray photoemission spectroscopy, Raman and infrared spectroscopy demonstrate that the CQDs combine with nanoplates via surface carbon-oxygen bonds. Wavelength resolved photoluminescence measurements show that the relative intensity of the blue (2.93 $\mathrm{eV}$ ) component of the emission associated with the nanoplates is significantly reduced by incorporating CQDs. We suggest that this reduction arises as a result of preferential trapping of the higher energy photoelectrons by surface defects on the CQDs.
\end{abstract}

Received 19th April 2018

Accepted 31st May 2018

DOI: $10.1039 / \mathrm{c} 8 \mathrm{ra0} 3359 \mathrm{e}$

rsc.li/rsc-advances

Achieving any of these routes requires sophisticated instru-

\section{Introduction}

The biological safety of GaN-based light-emitting diodes (LEDs) is a topic of on-going concern, following animal studies showing that the blue $(450-490 \mathrm{~nm})$ light from such sources can damage photoreceptor cells. ${ }^{1,2}$ Other studies have suggested that chronic blue light exposure may enhance the development of age-related macular degeneration and other pathologies.,4 Traditional methods for modifying the spectral output of LEDs include: (i) phosphor engineering, using a blue or near ultraviolet chip as the pump source to activate a phosphor. This strategy is heavily dependent on the availability of a suitable host structure and activators for the phosphor, and typically suffers from poor color rendering, poor thermal stability and the cost of rare earth doping; (ii) combining multiple chips, wherein red, green and blue emitting chips are integrated to produce a target spectrum. A challenge with this approach is that each chip contributes a relatively narrow spectral bandwidth to the overall emission, so any differences in their respective aging characteristics results in a color shift; (iii) onechip LEDs, involving multiple quantum well structures. These are currently hampered by the complicated epitaxy required for their fabrication, a low luminous efficacy and stability issues. ${ }^{5-7}$

${ }^{a}$ Research and Development Center for Solid State Lighting, Institute of Semiconductors, Chinese Academy of Sciences, Beijing, China.E-mail: jmli@semi.ac.cn

${ }^{b}$ School of Chemistry, University of Bristol, Bristol, UK BS8 1TS. E-mail: Mike. Ashfold@bristol.ac.uk mentation and time-consuming sample preparation. Developing a cost-effective, convenient and broadly applicable method for modifying the relative intensity of the blue component within a polychromatic light source remains a desirable objective.

Carbon quantum dots (CQDs) display both size and wavelength dependent photoluminescence (PL), which is inspiring intensive research - particularly in the design and application of multi-functional optical nanocomposites. ${ }^{8-12}$ CQDs offer the advantages of large surface areas, short effective charge-transfer lengths and available surface defects. The injection and extraction of electrons/holes can be controlled by appropriate surface functionalisation or by combining CQDs with a suitable matrix, thereby offering a route for switching between excitation and recombination processes. ${ }^{13}$ The present contribution reports on the structure, morphology and optical properties of nanocomposites involving blends of CQDs and zinc vanadium oxide hydroxide hydrate nanoplates (NPs). $\mathrm{Zn}_{3}(\mathrm{OH})_{2} \mathrm{~V}_{2} \mathrm{O}_{7} \cdot 2 \mathrm{H}_{2} \mathrm{O}$ itself shows fascinating optical properties, owing to its distinctive structure wherein alternate layers of $\mathrm{Zn}$ octahedra are connected by pyrovanadate groups. ${ }^{14,15}$ Previous studies of $\mathrm{Zn}_{3}(\mathrm{OH})_{2} \mathrm{~V}_{2} \mathrm{O}_{7} \cdot n \mathrm{H}_{2} \mathrm{O}$ samples with a range of morphologies have reported strong visible light emission in the range 400$700 \mathrm{~nm}$, and attributed energy levels in the band gap to zinc vacancies. ${ }^{16}$ Two-dimensional (2-D) ultrathin NP samples in general (of which $\mathrm{Zn}_{3}(\mathrm{OH})_{2} \mathrm{~V}_{2} \mathrm{O}_{7} \cdot 2 \mathrm{H}_{2} \mathrm{O}$ NPs are an obvious example) are attracting particular interest. These NPs are highly 
anisotropic and endowed with charge transfer and separation capabilities that are well suited for combining with CQDs in such a way as to modify the PL properties. ${ }^{17,18}$

Here we report the straight forward hydrothermal synthesis of $\mathrm{CQD} / \mathrm{Zn}_{3}(\mathrm{OH})_{2} \mathrm{~V}_{2} \mathrm{O}_{7} \cdot 2 \mathrm{H}_{2} \mathrm{O}$ NP composites. The structure and morphology of the as-prepared samples were characterized to confirm the incorporation of CQDs and $\mathrm{Zn}_{3}(\mathrm{OH})_{2} \mathrm{~V}_{2} \mathrm{O}_{7} \cdot 2 \mathrm{H}_{2} \mathrm{O}$ NPs. The PL properties of pure $\mathrm{Zn}_{3}(\mathrm{OH})_{2} \mathrm{~V}_{2} \mathrm{O}_{7} \cdot 2 \mathrm{H}_{2} \mathrm{O}$ and of the $\mathrm{CQD} / \mathrm{Zn}_{3}(\mathrm{OH})_{2} \mathrm{~V}_{2} \mathrm{O}_{7} \cdot 2 \mathrm{H}_{2} \mathrm{O} \mathrm{NP}$ composite samples were investigated, compared and contrasted to demonstrate the effective suppression of blue emission from the latter. Possible mechanisms for the observed modification of the PL properties are discussed.

\section{Experimental}

\section{Preparation of CQDs}

A mixture of $2.5 \mathrm{~g}$ sucrose $\left(\mathrm{C}_{12} \mathrm{H}_{22} \mathrm{O}_{11}\right)$ dissolved in $50 \mathrm{ml}$ deionized (DI) water was transferred into a $50 \mathrm{ml}$ Teflon-lined stainless steel autoclave and heated at $180{ }^{\circ} \mathrm{C}$ for 5 hours. After completion of the reaction, the resulting dark brown solution was centrifuged to yield CQDs.

\section{Synthesis of $\mathrm{Zn}_{3}(\mathrm{OH})_{2} \mathrm{~V}_{2} \mathrm{O}_{7} \cdot 2 \mathrm{H}_{2} \mathrm{O}$ nanoplates}

$1 \mathrm{mmol}$ vanadium pentoxide $\left(\mathrm{V}_{2} \mathrm{O}_{5}\right), 5 \mathrm{mmol}$ hexamethylenetetramine $\left(\mathrm{C}_{6} \mathrm{H}_{12} \mathrm{~N}_{4}\right), 1 \mathrm{mmol}$ zinc acetate dihydrate $\left(\mathrm{CH}_{3}\right.$ $\mathrm{COO})_{2} \mathrm{Zn} \cdot 2 \mathrm{H}_{2} \mathrm{O}$ and $3 \mathrm{mmol}$ sodium sulfate $\left(\mathrm{Na}_{2} \mathrm{SO}_{4}\right)$ were dissolved in $30 \mathrm{ml}$ DI water. The obtained homogeneous suspension was transferred into a $50 \mathrm{ml}$ Teflon-lined autoclave and heated in an oven at $140{ }^{\circ} \mathrm{C}$ for 24 hours. The resulting white product was washed and dried in a vacuum oven $(0.08$ Mpa) at $60{ }^{\circ} \mathrm{C}$ for 12 hours.

\section{Fabrication of $\mathrm{CQD} / \mathrm{Zn}_{3}(\mathrm{OH})_{2} \mathrm{~V}_{2} \mathrm{O}_{7} \cdot 2 \mathrm{H}_{2} \mathrm{O} \mathrm{NP}$ composites}

$10 \mathrm{ml}$ of CQD solution and $30 \mathrm{ml}$ of $\mathrm{Zn}_{3}(\mathrm{OH})_{2} \mathrm{~V}_{2} \mathrm{O}_{7} \cdot 2 \mathrm{H}_{2} \mathrm{O}$ solution with respective concentrations of 1 and $10 \mathrm{mg} \mathrm{ml}^{-1}$ were mixed and then placed in an autoclave. The mixture was heated in an oven at $80{ }^{\circ} \mathrm{C}$ for 5 hours. The product was washed with distilled water and dried in a vacuum oven $(0.08 \mathrm{MPa})$ at $50{ }^{\circ} \mathrm{C}$ for 12 hours.

\section{Characterization}

The structure, morphology and composition of the products were characterized by X-ray Diffraction (XRD), Field Emission Scanning Electron Microscopy (FE-SEM), High Resolution Transmission Electron Microscopy and Selected Area Electron Diffraction (HRTEM and SAED), X-ray Photoelectron Spectroscopy (XPS), Raman (532 nm excitation) and Fourier Transform Infrared (FTIR) Spectroscopy. The electronic absorption spectrum of the CQDs in aqueous solution was recorded using a UVVis spectrophotometer, and fluorescence emission spectra were measured following steady state/transient illumination at selected wavelengths ( $\lambda_{\mathrm{ex}}$, at $20 \mathrm{~nm}$ intervals in the range $320-$ $500 \mathrm{~nm}$ ) from the continuum emission of a high pressure xenon lamp. PL spectra of the $\mathrm{Zn}_{3}(\mathrm{OH})_{2} \mathrm{~V}_{2} \mathrm{O}_{7} \cdot 2 \mathrm{H}_{2} \mathrm{O}$ NP sample and the $\mathrm{CQD} / \mathrm{Zn}_{3}(\mathrm{OH})_{2} \mathrm{~V}_{2} \mathrm{O}_{7} \cdot 2 \mathrm{H}_{2} \mathrm{O}$ NP composites were measured using a Raman spectrometer with a He-Cd (325 nm) excitation laser at room temperature.

\section{Results and discussion}

The microstructure of the as-grown $\mathrm{CQD} / \mathrm{Zn}_{3}(\mathrm{OH})_{2} \mathrm{~V}_{2} \mathrm{O}_{7} \cdot 2 \mathrm{H}_{2} \mathrm{O}$ NP composite samples has been characterized by several complementary techniques. All diffraction peaks in the XRD spectrum match with the documented pattern for hexagonal phase $\mathrm{Zn}_{3}(\mathrm{OH})_{2} \mathrm{~V}_{2} \mathrm{O}_{7} \cdot 2 \mathrm{H}_{2} \mathrm{O}$ (JCPDs, no. 50-0570). The full-width at half maximum (FWHM) values of the peaks are sensitive to their $(h k l)$ indices, indicating a highly anisotropic structure. ${ }^{\mathbf{9}}$ No diffraction peak attributable to carbon was detected, reflecting the small volume fraction and low crystallinity of the
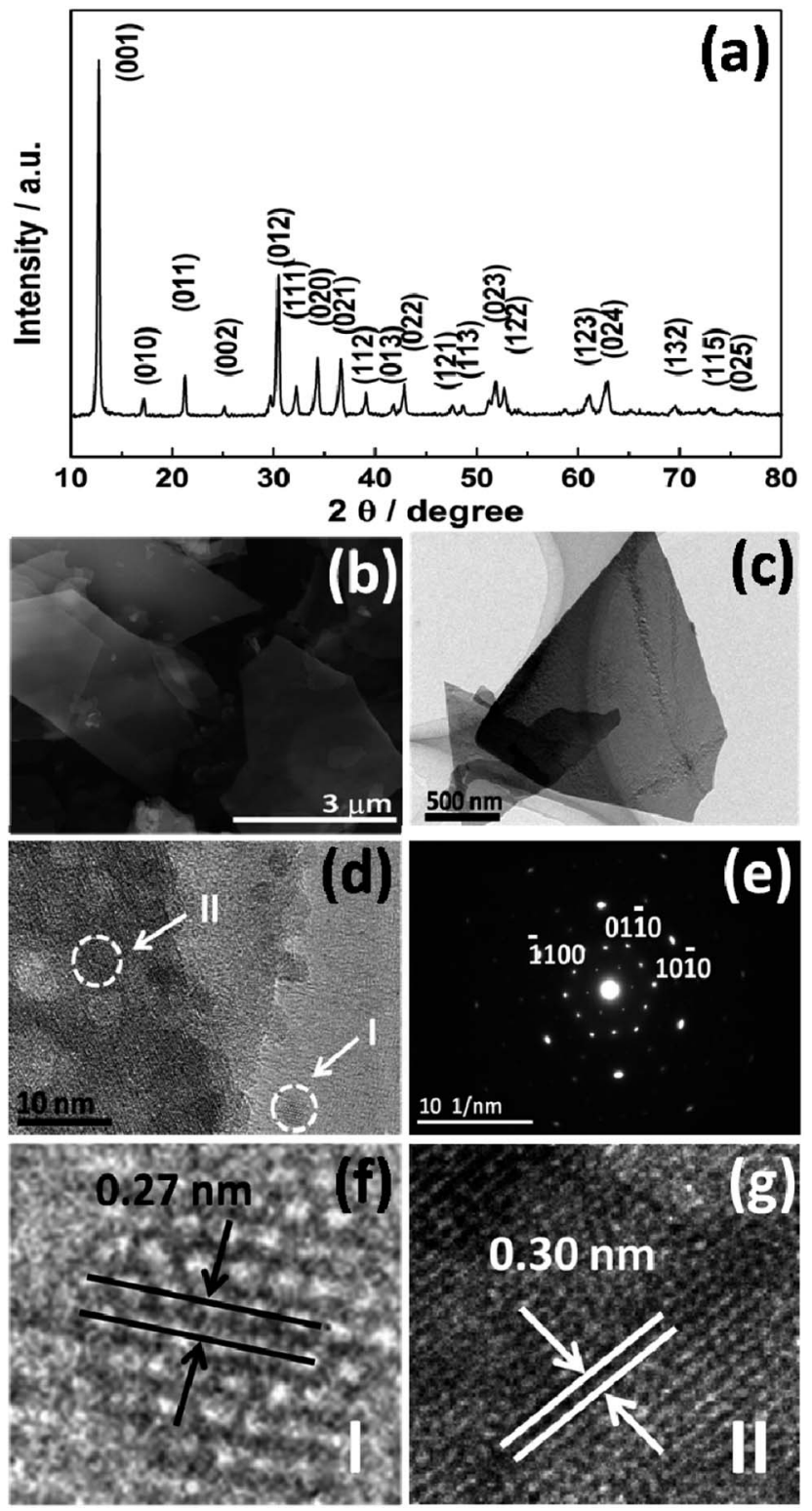

Fig. 1 (a) XRD pattern, (b) SEM, (c) TEM and (d, $f$ and g) HR-TEM images, along with (e) the SAED pattern of the as-prepared CQD/ $\mathrm{Zn}_{3}(\mathrm{OH})_{2} \mathrm{~V}_{2} \mathrm{O}_{7} \cdot 2 \mathrm{H}_{2} \mathrm{O}$ NP composites. 

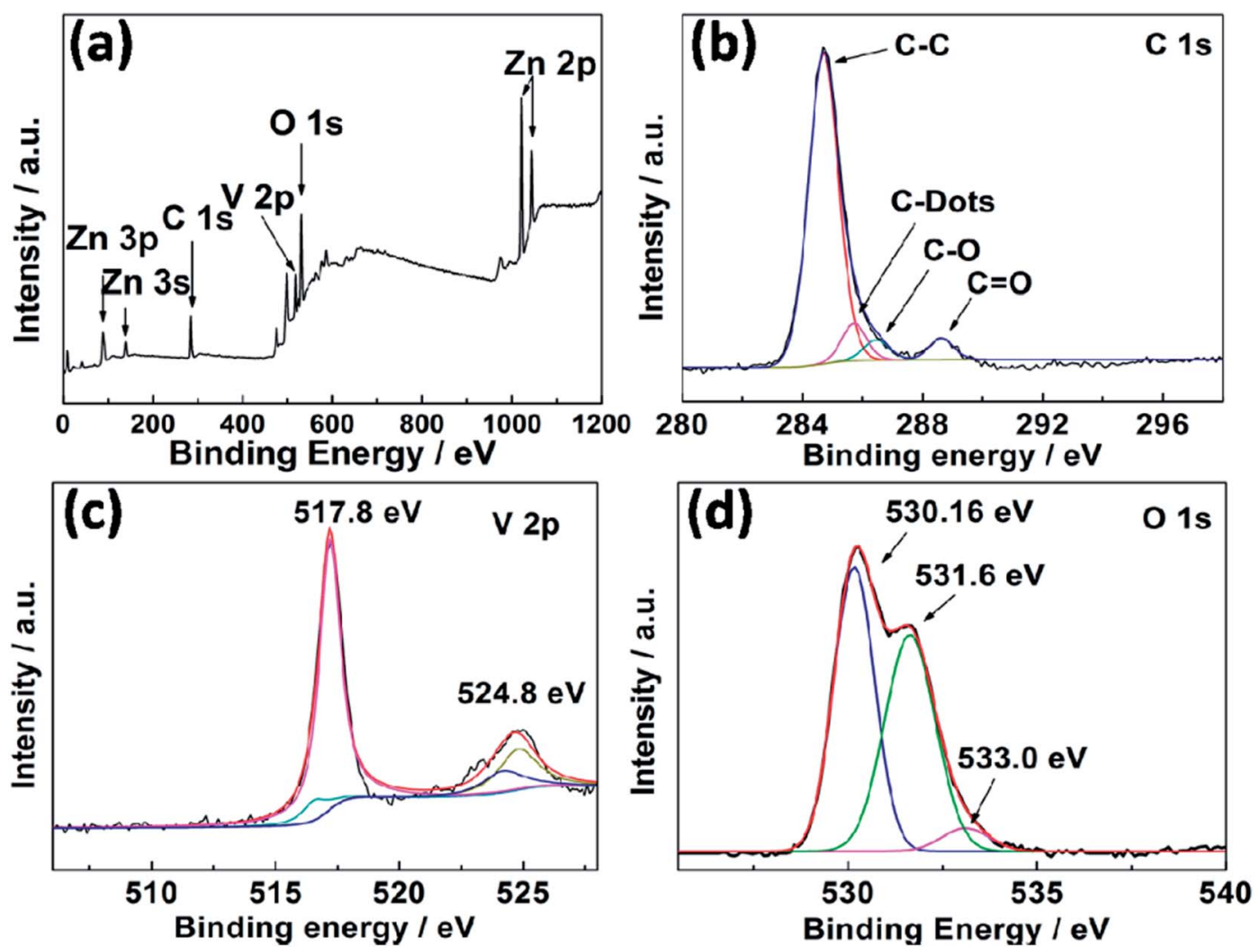

Fig. 2 (a) Survey XPS spectrum of the as-prepared $C Q D / Z n_{3}(O H)_{2} V_{2} \mathrm{O}_{7} \cdot 2 \mathrm{H}_{2} \mathrm{O} N P$ composites along with expanded views of the (b) $\mathrm{C} 1 \mathrm{~s}$, (c) $\vee 2 \mathrm{p}$ and (d) $\mathrm{O}$ 1s binding regions and illustrative deconvolutions as described in the text.

CQDs (Fig. 1(a)). Numerous NPs with smooth surfaces, regular edges and lateral dimensions of the order of several to tens of microns are observable in the SEM image (Fig. 1(b)), which bodes well for applications that might require high levels of surface interactions. ${ }^{20}$

TEM and SAED analysis revealed additional subtleties concerning these $\mathrm{CQD} / \mathrm{Zn}_{3}(\mathrm{OH})_{2} \mathrm{~V}_{2} \mathrm{O}_{7} \cdot 2 \mathrm{H}_{2} \mathrm{O}$ NP composites. The low resolution TEM image (Fig. 1(c)) accords with the SEM results and the associated SAED pattern (Fig. 1(e)) exhibits clear diffraction spots in a hexagonal configuration, showing that the dominant phase is hexagonal $(P \overline{3} m 1)$ with a high degree of crystallinity, and that the preferred growth direction is normal to [0001]. The HRTEM image (Fig. 1(d)) shows that the CQDs are well dispersed and have small diameters in the range 5-7 $\mathrm{nm}$. Lattice fringes associated with both CQDs (I) and $\mathrm{Zn}_{3}(\mathrm{OH})_{2} \mathrm{~V}_{2^{-}}$ $\mathrm{O}_{7} \cdot 2 \mathrm{H}_{2} \mathrm{O}$ NPs (II) can be seen in the enlarged patterns (Fig. 1(f) and (g), respectively). The $0.27 \mathrm{~nm}$ lattice spacing is associated with the CQDs, which is a little larger than the spacing of the (020) plane of graphitic carbon $(0.25 \mathrm{~nm})$, while the $0.30 \mathrm{~nm}$ spacing corresponds to the (012) plane of the $\mathrm{Zn}_{3}(\mathrm{OH})_{2} \mathrm{~V}_{2} \mathrm{O}_{7^{-}}$ $\cdot 2 \mathrm{H}_{2} \mathrm{O}$ NPs. ${ }^{21}$

The composition and the surface properties of the CQD/ $\mathrm{Zn}_{3}(\mathrm{OH})_{2} \mathrm{~V}_{2} \mathrm{O}_{7} \cdot 2 \mathrm{H}_{2} \mathrm{O}$ NP composites were also investigated by XPS. The full survey spectrum (Fig. 2(a)) indicates the presence of zinc (Zn 2p), carbon (C 1s), vanadium (V 2p) and oxygen (O $1 \mathrm{~s})$. An enlarged view of the $\mathrm{C} 1 \mathrm{~s}$ binding energy region is shown in Fig. 2(b), wherein the peaks were fitted as four components corresponding to $\mathrm{C}-\mathrm{C}, \mathrm{C}-\mathrm{dots}, \mathrm{C}-\mathrm{O}$ and $\mathrm{C}=\mathrm{O}$ bonds, respectively. ${ }^{22,23}$ No peaks attributable to $\mathrm{Zn}-\mathrm{C}$ or $\mathrm{V}-\mathrm{C}$ bonds were identified, implying that the CQDs are not present as dopants in the composite material. Fig. 2 (c) shows $\mathrm{V} 2 \mathrm{p}_{3 / 2}$ and $\mathrm{V} 2 \mathrm{p}_{1 / 2}$ peaks at 517.8 and $524.8 \mathrm{eV}$, respectively, attributable to the $\mathrm{V}-\mathrm{O}$ bonds in the $\left[\mathrm{V}_{2} \mathrm{O}_{7}\right]^{4-}$ anions. Peaks at binding energies associated with $\mathrm{O} 1 \mathrm{~s}$ are identified at 530.2, 531.6 and $533.0 \mathrm{eV}$ (Fig. 2(d)) and ascribed to $\mathrm{Zn}-\mathrm{O}$ and $\mathrm{V}-\mathrm{O}$ bonding, to $\mathrm{C}=\mathrm{O}$ bonding and to $\mathrm{H}_{2} \mathrm{O}$, respectively. ${ }^{24-26}$

FTIR and Raman spectra of the as-prepared $\mathrm{Zn}_{3}(\mathrm{OH})_{2} \mathrm{~V}_{2} \mathrm{O}_{7^{-}}$ $\cdot 2 \mathrm{H}_{2} \mathrm{O}$ NPs and the CQD $/ \mathrm{Zn}_{3}(\mathrm{OH})_{2} \mathrm{~V}_{2} \mathrm{O}_{7} \cdot 2 \mathrm{H}_{2} \mathrm{O}$ NP composites are compared in Fig. 3 . The clear Raman peaks at 250, 329, 434, 478, 796 and $869 \mathrm{~cm}^{-1}$ (Fig. 3(a)) are all characteristic of hexagonal $\mathrm{Zn}_{3}(\mathrm{OH})_{2} \mathrm{~V}_{2} \mathrm{O}_{7} \cdot 2 \mathrm{H}_{2} \mathrm{O}$. No extra features attributable
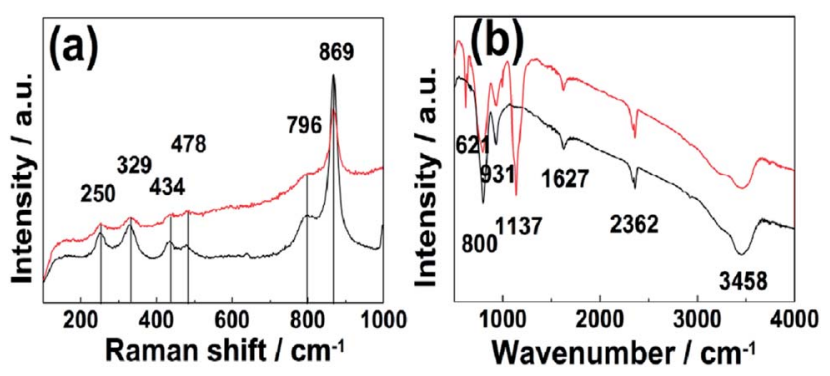

Fig. 3 (a) Raman and (b) FTIR spectra of the as-prepared $\mathrm{Zn}_{3}(\mathrm{OH})_{2^{-}}$ $\mathrm{V}_{2} \mathrm{O}_{7} \cdot 2 \mathrm{H}_{2} \mathrm{O} \mathrm{NPs}$ (black) and of the $\mathrm{CQD} / \mathrm{Zn}_{3}(\mathrm{OH})_{2} \mathrm{~V}_{2} \mathrm{O}_{7} \cdot 2 \mathrm{H}_{2} \mathrm{O} \mathrm{NP}$ composite (red). 


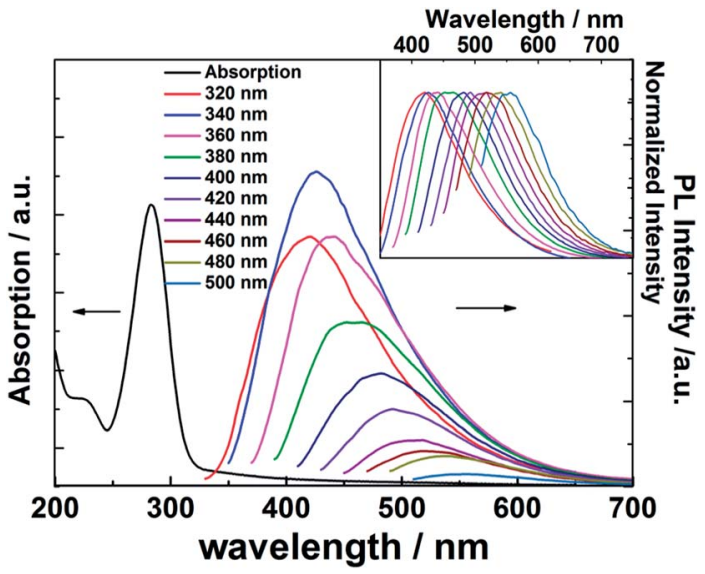

Fig. 4 UV-Vis absorption and PL spectra of the as-prepared CQDs following illumination at progressively longer excitation wavelengths (stepped in $20 \mathrm{~nm}$ increments across the range $320 \leq \lambda_{\text {ex }} \leq 500 \mathrm{~nm}$ ). The corresponding normalized emission spectra are shown in the inset.

to bonding in the $\mathrm{CQD} / \mathrm{Zn}_{3}(\mathrm{OH})_{2} \mathrm{~V}_{2} \mathrm{O}_{7} \cdot 2 \mathrm{H}_{2} \mathrm{O} \mathrm{NP}$ composites were observed in this region, indicating the stability of the matrix structure. ${ }^{27,28}$ FTIR features attributable to intrinsic $\mathrm{Zn}_{3}(\mathrm{OH})_{2} \mathrm{~V}_{2} \mathrm{O}_{7} \cdot 2 \mathrm{H}_{2} \mathrm{O}$ NPs are found in two wavenumber regions. Peaks in the $600-950 \mathrm{~cm}^{-1}$ region are associated with symmetric and asymmetric $\mathrm{V}-\mathrm{O}-\mathrm{Zn}$ and $\mathrm{V}-\mathrm{O}-\mathrm{V}$ vibrations, while both symmetric stretching and bending vibrations of $\mathrm{H}_{2} \mathrm{O}$ and the vibrations of any surface adsorbed $\mathrm{CO}_{2}$ molecules typically fall at higher wavenumber (in the range 1600$\left.3600 \mathrm{~cm}^{-1}\right) .{ }^{9,29}$ The additional features at 621 and $1137 \mathrm{~cm}^{-1}$, which do not match with the documented peaks of hexagonal $\mathrm{Zn}_{3}(\mathrm{OH})_{2} \mathrm{~V}_{2} \mathrm{O}_{7} \cdot 2 \mathrm{H}_{2} \mathrm{O}$ and can be associated with $\mathrm{C}-\mathrm{O}$ and $\mathrm{C}=\mathrm{O}$ stretching vibrations, ${ }^{30}$ hint at contributions from the CQDs. Thus it is tempting to propose that the $\mathrm{CQD} / \mathrm{Zn}_{3}(\mathrm{OH})_{2} \mathrm{~V}_{2} \mathrm{O}_{7^{-}}$ $\cdot 2 \mathrm{H}_{2} \mathrm{O} \mathrm{NP}$ composites are constituted by the formation of $\mathrm{C}-\mathrm{O}$ and $\mathrm{C}=\mathrm{O}$ bonds between the surfaces of the CQDs and $\mathrm{Zn}_{3}(-$ $\mathrm{OH})_{2} \mathrm{~V}_{2} \mathrm{O}_{7} \cdot 2 \mathrm{H}_{2} \mathrm{O}$ NPs.

The UV-Vis absorption and fluorescent properties of the CQDs were investigated in aqueous solution: results are shown in Fig. 4. The absorption curve (black line) shows an intense peak at $\sim 284 \mathrm{~nm}$ that can be assigned to $\mathrm{C}=\mathrm{C}$ bond localized $\pi^{*} \leftarrow \pi$ excitations and a much weaker tail stretching to longer wavelengths consistent with a $\mathrm{C}=\mathrm{O}$ bond localized $\pi^{*} \leftarrow \mathrm{n}$ transition. ${ }^{31,32}$ The PL spectra taken at progressively longer excitation wavelengths $\left(\lambda_{\mathrm{ex}}\right)$, stepping in $20 \mathrm{~nm}$ increments between 320 and $500 \mathrm{~nm}$ (colored line), reveal a clear $\lambda_{\mathrm{ex}^{-}}$ dependence to the peak emission wavelength $\left(\lambda_{\mathrm{em}}\right)$ and its intensity, though we recognize that the latter dependence must be convoluted with the $\lambda_{\mathrm{ex}}$-dependent excitation light intensity. As noted elsewhere, such observations point to the existence of a range of emission traps at surface sites on the CQDs. ${ }^{33-35}$

Fig. 5 shows further analysis of the CQD PL data. In all cases, the energy corresponding to the peak of the emission spectrum $\left(E_{\text {em }}\right)$ lies below the excitation energy $\left(E_{\text {ex }}\right)$, i.e. below the $E_{\text {em }}=$ $E_{\text {ex }}$ line, confirming that the Stokes' shift is positive throughout the range $320 \leq \lambda_{\text {ex }} \leq 500 \mathrm{~nm}$. The origin of the phenomenon is not yet entirely understood, but it is generally assumed that the

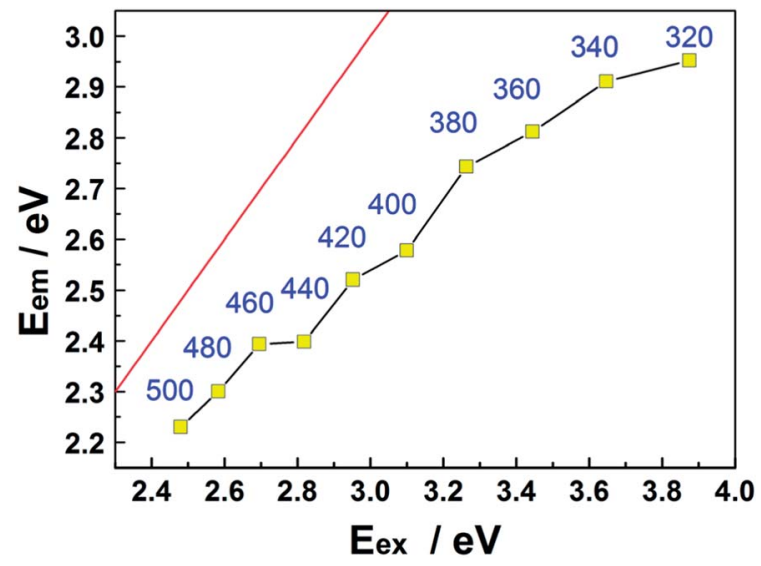

Fig. 5 Plot showing the variation of $E_{\mathrm{em}}$ with $E_{\mathrm{ex}} . E_{\mathrm{em}}=E_{\mathrm{ex}}$ is shown by the red line, and each data point is additionally labelled by the corresponding $\lambda_{\text {ex }}$ value (in $\mathrm{nm}$ ).

emission and its shift with $E_{\text {ex }}$ arise from the radiative recombination of excitons located at surface energy traps. ${ }^{36-38}$

Data such as those shown in Fig. 4 and 5 have attracted interest, both from a fundamental perspective and in the context of practical applications. These data for the as-prepared CQDs are now compared with the room temperature PL spectra $\left(\lambda_{\text {ex }}=325 \mathrm{~nm}\right)$ of a CQD $/ \mathrm{Zn}_{3}(\mathrm{OH})_{2} \mathrm{~V}_{2} \mathrm{O}_{7} \cdot 2 \mathrm{H}_{2} \mathrm{O}$ NP composite sample and of pure $\mathrm{Zn}_{3}(\mathrm{OH})_{2} \mathrm{~V}_{2} \mathrm{O}_{7} \cdot 2 \mathrm{H}_{2} \mathrm{O}$ shown in Fig. 6 (red and blue curves, respectively). Both spectra show two broad emission bands, centered at energies below the band gap of $\mathrm{Zn}_{3}(\mathrm{OH})_{2} \mathrm{~V}_{2} \mathrm{O}_{7} \cdot 2 \mathrm{H}_{2} \mathrm{O}(\sim 3.35 \mathrm{eV}) .{ }^{\mathbf{1 4 , 1 6 , 3 9}}$ As noted elsewhere, these emissions are likely to arise from energy levels in the band gap induced by local defects such as zinc vacancies. ${ }^{16}$ As Fig. 6 also shows, these PL spectra can both be decomposed as the sum of two Gaussian features centered at 2.33 and $2.93 \mathrm{eV}$, but the relative peak intensities are substantially modified when CDQs are attached. Specifically, the relative intensity of the higher

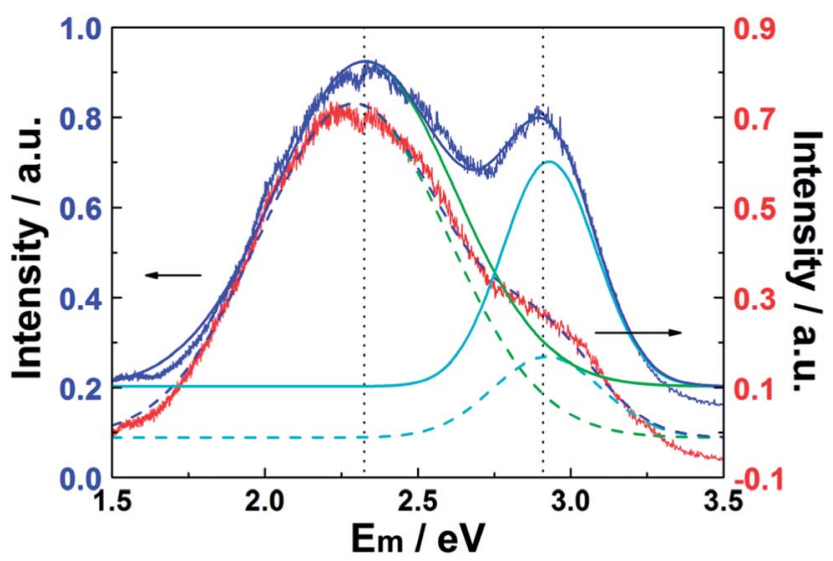

Fig. $6 \mathrm{PL}$ spectra $\left(\lambda_{\text {ex }}=325 \mathrm{~nm}\right)$ of the as-prepared $\mathrm{Zn}_{3}(\mathrm{OH})_{2} \mathrm{~V}_{2} \mathrm{O}_{7}$ $\cdot 2 \mathrm{H}_{2} \mathrm{O}$ NPs (blue) and CQD/ $\mathrm{Zn}_{3}(\mathrm{OH})_{2} \mathrm{~V}_{2} \mathrm{O}_{7} \cdot 2 \mathrm{H}_{2} \mathrm{O}$ NP composites (red). The corresponding best-fits in terms of a sum of two Gaussian features centered at 2.33 and $2.93 \mathrm{eV}$ are shown by the solid and dashed lines, respectively. The two PL spectra have been normalized to the same peak intensity, but have been offset vertically by $0.1 \mathrm{a}$.u. for display purposes. 


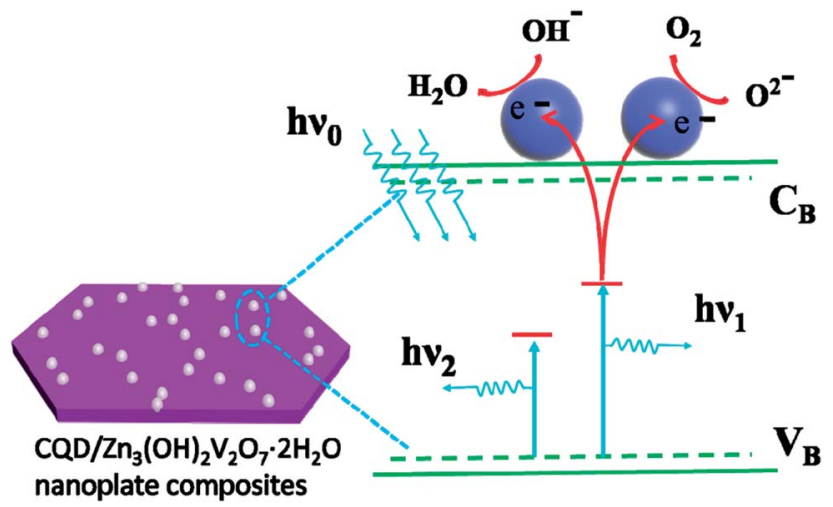

Fig. 7 Schematic illustration of the mechanism for the modification of the PL from CQD/Zn $3(\mathrm{OH})_{2} \mathrm{~V}_{2} \mathrm{O}_{7} \cdot 2 \mathrm{H}_{2} \mathrm{O}$ NP composite samples.

energy (blue) emission feature is reduced by $\sim 50 \%$ relative to that of the lower energy feature.

Fig. 7 suggests, schematically, how the presence of the CQDs could influence the PL spectrum of the CQD $/ \mathrm{Zn}_{3}(\mathrm{OH})_{2}$ $\mathrm{V}_{2} \mathrm{O}_{7} \cdot 2 \mathrm{H}_{2} \mathrm{O}$ NP composite samples. The CQDs, which are both excellent electron donors and electron acceptors, are well dispersed on the surface of the $\mathrm{Zn}_{3}(\mathrm{OH})_{2} \mathrm{~V}_{2} \mathrm{O}_{7} \cdot 2 \mathrm{H}_{2} \mathrm{O}$ NPs. Incident $325 \mathrm{~nm}$ photons (with energy $h \nu_{0}$ ) are absorbed by the $\mathrm{CQD} / \mathrm{Zn}_{3}(\mathrm{OH})_{2} \mathrm{~V}_{2} \mathrm{O}_{7} \cdot 2 \mathrm{H}_{2} \mathrm{O} \mathrm{NP}$ composite, generating photoelectrons. Some of these result in light emission from the $\mathrm{Zn}_{3}(\mathrm{OH})_{2} \mathrm{~V}_{2} \mathrm{O}_{7} \cdot 2 \mathrm{H}_{2} \mathrm{O}$ NPs themselves at energies $h \nu_{1}(2.33 \mathrm{eV})$ and $h \nu_{2}(2.93 \mathrm{eV})$, but other photoelectrons transfer to lower energy sites on the surface of the CQDs resulting in (relatively) increased visible and reduced blue emission. ${ }^{11,40-43}$ Such proposed selective absorption of photoelectrons by the CQDs lacks systematic definition at this time, but we speculate that the CQDs support a high density of energy states (as a result of size quantization, irregularly spaced surface defects and adsorbed functional groups) that offer a wide range of chemical potentials and enable modification of the PL emission. Clearly, there is a pressing need for more detailed investigations of, for example, the excited state dynamics and recombination processes in $\mathrm{CQD} / \mathrm{Zn}_{3}(\mathrm{OH})_{2} \mathrm{~V}_{2} \mathrm{O}_{7} \cdot 2 \mathrm{H}_{2} \mathrm{O}$ NP composite materials.

\section{Conclusions}

We report the characterization of $\mathrm{CQD} / \mathrm{Zn}_{3}(\mathrm{OH})_{2} \mathrm{~V}_{2} \mathrm{O}_{7} \cdot 2 \mathrm{H}_{2} \mathrm{O} \mathrm{NP}$ composites prepared via a simple hydrothermal process. The CQDs appear to be accommodated through $\mathrm{C}-\mathrm{O}$ and $\mathrm{C}=\mathrm{O}$ bonds to the surfaces of the $\mathrm{Zn}_{3}(\mathrm{OH})_{2} \mathrm{~V}_{2} \mathrm{O}_{7} \cdot 2 \mathrm{H}_{2} \mathrm{O}$ NPs. Further, PL measurements show that CQDs can be used to modify the PL properties of $\mathrm{Zn}_{3}(\mathrm{OH})_{2} \mathrm{~V}_{2} \mathrm{O}_{7} \cdot 2 \mathrm{H}_{2} \mathrm{O}$ NPs, specifically reducing the relative intensity of the blue component within the overall emission - thereby ameliorating the possibility of blue-light induced damage to, for example, photoreceptor cells. Such novel composites offer new insights into the design of efficient optoelectrical devices and could serve to inspire future technological applications in this field.

\section{Conflicts of interest}

There are no conflicts to declare.

\section{Acknowledgements}

This work was supported by the National Natural Science Foundation of China (Grant No. Y612040000). The authors are grateful to Lian C. Wang, Hai Z. Xie, and Jia Q. Pan for their many and varied contributions to the described work.

\section{References}

1 M. Hatori, C. Gronfier, R. N. Van Gelder, P. S. Bernstein, J. Carreras, S. Panda, F. Marks, D. Sliney, C. E. Hunt, T. Hirota, T. Furukawa and K. Tsubota, npj Aging Mech. Dis., 2017, 3, 9.

2 A. Krigel, M. Berdugo, E. Picard, R. Levy-Boukris, I. Jaadane, L. Jonet, M. Dernigoghossian, C. Andrieu-Soler, A. Torriglia and F. Behar-Cohen, Neuroscience, 2016, 339, 296-307.

3 F. Behar-Cohen, C. Martinsons, F. Viénot, G. Zissis, A. Barlier-Salsi, J. P. Cesarini, O. Enouf, M. Garcia, S. Picaud and D. Attia, Prog. Retinal Eye Res., 2011, 30, 239257.

4 I. Jaadane, P. Boulenguez, S. Chahory, S. Carré, M. Savoldelli, L. Jonet, F. Behar-Cohen, C. Martinsons and A. Torriglia, Free Radical Biol. Med., 2015, 84, 373-384.

5 S. Ye, F. Xiao, Y. X. Pan, Y. Y. Ma and Q. Y. Zhang, Mater. Sci. Eng., $R$, 2010, 71, 1-34.

6 J. Cho, J. H. Park, J. K. Kim and E. F. Schubert, Laser Photonics Rev., 2017, 11, 1600147.

7 P. F. Smet and J. J. Joos, Nat. Mater., 2017, 16, 500.

8 S. Y. Lim, W. Shen and Z. Gao, Chem. Soc. Rev., 2015, 44, 362381.

9 J. Pan, Y. Sheng, J. Zhang, J. Wei, P. Huang, X. Zhang and B. Feng, J. Mater. Chem. A, 2014, 2, 18082-18086.

10 S. Zhu, Y. Song, X. Zhao, J. Shao, J. Zhang and B. Yang, Nano Res., 2015, 8, 355-381.

11 B. Cui, X.-T. Feng, F. Zhang, Y.-L. Wang, X.-G. Liu, Y.-Z. Yang and H.-S. Jia, New Carbon Mater., 2017, 32, 385-401.

12 P. Namdari, B. Negahdari and A. Eatemadi, Biomed. Pharmacother., 2017, 87, 209-222.

13 X. Wang, L. Cao, F. Lu, M. J. Meziani, H. Li, G. Qi, B. Zhou, B. A. Harruff, F. Kermarrec and Y.-P. Sun, Chem. Commun., 2009, 3774-3776, DOI: 10.1039/B906252A.

14 Q. Wang, L. Zheng, Y. Bai, J. Zhao, F. Wang, R. Zhang, H. Huang and B. Su, Appl. Surf. Sci., 2015, 347, 602-609.

15 H. Guo, D. Guo, Z. Zheng, W. Wen and J. Chen, J. Mater. Res., 2014, 29, 2934-2941.

16 S. Ni, G. Zhou, X. Wang, X. Sun, F. Yang, Y. Liu and D. He, Mater. Chem. Phys., 2010, 120, 426-430.

17 S. Hu and X. Wang, Chem. Soc. Rev., 2013, 42, 5577-5594.

18 S. Han, L. Hu, Z. Liang, S. Wageh, A. A. Al-Ghamdi, Y. Chen and X. Fang, Adv. Funct. Mater., 2014, 24, 5719-5727.

19 F. Wang, W. Wu, X. Sun, S. Song, Y. Xing, J. Wang, D. Yu and Z. Su, Mater. Charact., 2013, 86, 139-145. 
20 R. Mas-Balleste, C. Gomez-Navarro, J. Gomez-Herrero and F. Zamora, Nanoscale, 2011, 3, 20-30.

21 G. Yang, M. Wu and C. Wang, ACS Appl. Mater. Interfaces, 2016, 8, 23746-23754.

22 H. Yu, Y. Zhao, C. Zhou, L. Shang, Y. Peng, Y. Cao, L.-Z. Wu, C.-H. Tung and T. Zhang, J. Mater. Chem. A, 2014, 2, 33443351.

23 Q. Liang, W. Ma, Y. Shi, Z. Li and X. Yang, Carbon, 2013, 60, 421-428.

24 H. Guo, J. Chen, W. Weng and S. Li, Appl. Surf. Sci., 2011, 257, 3920-3923.

25 R. Gopal and C. Calvo, Can. J. Chem., 1973, 51, 1004-1009.

26 S. Ni, G. Zhou, S. Lin, X. Wang, Q. Pan, F. Yang and D. He, Mater. Lett., 2009, 63, 2459-2461.

27 E. Hryha, E. Rutqvist and L. Nyborg, Surf. Interface Anal., 2012, 44, 1022-1025.

28 L. Yang, Y. Tang, L. Tong, H. Zhou, J. Ding, T. Fan and D. Zhang, Appl. Surf. Sci., 2015, 346, 115-123.

29 M. Ren, J. Song, Y. Shi, Y. Xiang and G. Hu, J. Cryst. Growth, 2014, 402, 119-123.

30 M. Shim, S. V. Shilov, M. S. Braiman and P. Guyot-Sionnest, J. Phys. Chem. B, 2000, 104, 1494-1496.

31 J. Ke, X. Li, Q. Zhao, B. Liu, S. Liu and S. Wang, J. Colloid Interface Sci., 2017, 496, 425-433.
32 X. Jia, J. Li and E. Wang, Nanoscale, 2012, 4, 5572-5575.

33 N. Baker Sheila and A. Baker Gary, Angew. Chem., Int. Ed., 2010, 49, 6726-6744.

34 S. K. Das, Y. Liu, S. Yeom, D. Y. Kim and C. I. Richards, Nano Lett., 2014, 14, 620-625.

35 Y.-P. Sun, B. Zhou, Y. Lin, W. Wang, K. A. S. Fernando, P. Pathak, M. J. Meziani, B. A. Harruff, X. Wang, H. Wang, P. G. Luo, H. Yang, M. E. Kose, B. Chen, L. M. Veca and S.-Y. Xie, J. Am. Chem. Soc., 2006, 128, 7756-7757.

36 S. Zhuo, M. Shao and S.-T. Lee, ACS Nano, 2012, 6, 10591064.

37 A.-M. Alam, B.-Y. Park, Z. K. Ghouri, M. Park and H.-Y. Kim, Green Chem., 2015, 17, 3791-3797.

38 J. W. Arbogast, C. S. Foote and M. Kao, J. Am. Chem. Soc., 1992, 114, 2277-2279.

39 D. L. Wood and J. Tauc, Phys. Rev. B, 1972, 5, 3144-3151.

40 K. T. Shimizu, W. K. Woo, B. R. Fisher, H. J. Eisler and M. G. Bawendi, Phys. Rev. Lett., 2002, 89, 117401.

41 A. Henglein, A. Kumar, E. Janata and H. Weller, Chem. Phys. Lett., 1986, 132, 133-136.

42 P. V. Kamat, I. Bedja and S. Hotchandani, J. Phys. Chem., 1994, 98, 9137-9142.

43 P. V. Kamat, J. Am. Chem. Soc., 1991, 113, 9705-9707. 